\title{
Epistemic Virtues Versus Ethical Values in the Financial Services Sector
}

\author{
Emma Borg ${ }^{1}$ (D) Bradford Hooker ${ }^{2}$
}

Received: 30 November 2016/Accepted: 12 April 2017/Published online: 25 April 2017

(c) The Author(s) 2017. This article is an open access publication

\begin{abstract}
In his important recent book, Ethics and the Global Financial Crisis: Why Incompetence is Worse than Greed (2015), Boudewijn de Bruin argues that a key element of the global financial crisis of 2007-2008 was a failure of epistemic (i.e. knowledge-based) virtue. To improve matters, then, de Bruin argues we need to focus on the acquisition and exercise of epistemic virtues, rather than to focus on a more ethical culture for banking per se. Whilst this is an interesting suggestion and it is indeed very plausible that an increased focus on proper knowledgerelated behaviour will be part of a solution, we are sceptical both about de Bruin's overarching theoretical claims and about his practical suggestions for change. Instead we argue that change in this sector is best promoted by reconceiving of the relationship between financial institutions and the societies they serve, and that this is fundamentally not an epistemic but a moral issue.
\end{abstract}

Keywords Ethical values in financial services - Responses to the financial crisis · Financial literacy

Emma Borg

e.g.n.borg@ reading.ac.uk

Bradford Hooker

b.w.hooker@reading.ac.uk

1 Philosophy Department, Reading Centre for Cognition Research, University of Reading, Reading RG6 6AA, UK

2 Philosophy Department, University of Reading, Reading RG6 6AA, UK

\section{Introduction}

The global financial crisis of 2007-2008 was one of the most significant events of recent decades. However, very little has been written from a philosophical perspective on what was to blame for causing this event and how to avoid a repeat crisis in the future. A welcome exception to this lacuna is Boudewijn de Bruin's book Ethics and the Global Financial Crisis: Why Incompetence is Worse than Greed (2015). De Bruin's book manifests impressive philosophical expertise and extensive knowledge about economics in general and financial services in particular. Moreover, the book marshals intriguing arguments to make novel suggestions about the nature of the financial crisis and about how to reduce the risk of future ones.

The main thesis of de Bruin's book is that problems in the financial services sector leading up to the crisis, and on display in subsequent scandals in the sector, are more accurately described as failures of epistemic (i.e. knowledge-related) virtue than as failures of moral virtue. As the sub-title of the book suggests, his idea is that incompetence (and in particular epistemic incompetence) is more problematic in the sector than greed (and, we take it, more problematic than any other relevant non-epistemic moral failing).

The idea that epistemic failings had some role to play in the crisis is of course unarguable. For instance, no one could object to the idea that the firms that bought and sold the highly complex mortgage-backed security products that bundled up over-leveraged sub-prime US mortgages should have been more epistemically diligent in discovering the real risk associated with those products. However, from the recognition that epistemic failures had some role to play in the crisis, it is a significant step to the theoretical model, and practical implications, that de Bruin recommends. In 
particular, beyond the unarguable role for improved epistemic practices, de Bruin also needs to establish two further claims:

- First, that the undeniable requirement that epistemic practices be improved is best understood in terms of the theoretical framework of epistemic virtue theory (of the kind that de Bruin offers).

- Second, that the epistemic virtue theory thus elaborated provides the best way to think about the crisis and subsequent scandals.

In this paper, we argue against both these further claims. That is, we argue that the move to epistemic virtue theory is unnecessary and that the evident epistemic failures were no more than one small part of the story, with the overarching problem being one of a moral, not epistemic, failure. Furthermore, this argument matters, because the way that policy analysts conceive of the crisis will affect the moves they take to be necessary to help safeguard against future problems. Thus, as we will explain, because we disagree with de Bruin about the best way to conceive of the crisis, we also disagree with him about the steps needed to ameliorate matters in this area.

The structure of the paper is as follows: $\S 1$ provides an overview of de Bruin's account. $\$ 2$ turns to the question of whether or not the evident epistemic failings on display both pre- and post-crisis are best understood in terms of epistemic virtue theory and this section goes on to offer some initial reasons to be sceptical about this claim. Then $\S 3$ turns to our main argument: that de Bruin is mistaken to conceive of the crisis in terms of a failure of epistemic virtue. We argue, first, that de Bruin has failed to provide an appropriate normative ground for the epistemic virtues to which he appeals, second, that he has failed to knock out relevant alternatives to his proposed account, and third, that an account in terms of epistemic virtues provides no clear pathway to practical improvements. Furthermore, as we argue in $\S 4$, the alternatives to de Bruin's approach give rise to a different way to view the crisis-as emerging from a failure by the large financial institutions to properly recognize and act in line with their special social role. We argue that de Bruin is wrong to dismiss the idea that banks have a special status within the business world and that recognition of this special status helps to clarify the kinds of concrete steps which need to be taken both to rebuild warranted public trust in the sector and to help safeguard against future financial crises. We close by restating why this issue matters-why it is important that we not only identify the true nature of the failings during and after the global financial crisis but also take steps to restore warranted trust in the sector by safeguarding against these failings in the future.

\section{The Nature of the Global Financial Crisis}

The fact that many banks needed rescuing during the crisis by the state or by foreign investors/states has undermined public confidence in their competence. And scandals in the sector, such as mis-selling of payment protection insurance and colluding in fixing the Libor, have led the public to believe that banks prioritize profit at the cost of any other consideration (short of illegality). ${ }^{1}$ To compound matters here, the standard mechanisms for curbing poor behaviour-reputational damage and the imposition of financial penalties-are widely held to be insufficiently effective. ${ }^{2}$

Another complaint against the banks is that they "privatized gains and socialized losses". Over a number of years, banks made huge profits by taking unreasonable risks. They sold very risky sub-prime mortgages and let their capital ratios get very low. These turned out to be risks with bad consequences. And these bad consequences were not just for the people who owned or worked for the banks. Because the banks were so foundational to our economy that they were thought to be "too big to let fail", governments decided to prevent failure in most cases. So the bad consequences of selling very risky sub-prime mortgages and letting banks' capital ratios get very low were also for society's tax payers, who had to pick up the bill.

Now if the banks had been willing to take on the unreasonable risks precisely because of an expectation on

\footnotetext{
${ }^{1}$ Of course, one might think that pursuit of shareholder value as the primary objective is written into law, so that banks (along with all other corporations) have no choice but to pursue profit above all else. However, legislative frameworks do recognise the existence of secondary duties. For instance, Section 172 of the UK Companies Act 2006 notes that company directors must have regard to "the interests of the company's employees, the company's relationships with its suppliers and customers, the impact of the company's operations on the community and the environment, and the desirability of the company maintaining a reputation of high standards". It is then the capacity of banks to balance these primary and secondary duties which we take it the public have lost confidence in post-crisis.

${ }^{2}$ For instance surveys apparently show an on-going acceptance within the industry of misbehaviour (e.g. Wall Street, Fleet Street and Main Street: Corporate Integrity at a Crossroads 2012) and despite record levels of fines imposed on the sector, scandals continue to come to light. As the G30's recent report Banking Conduct and Culture (2015, p. 21) states, "At the time this report was drafted, cumulative fines for the largest global banks exceeded US $\$ 300$ billion since the financial crisis (McLannahan 2015). The extent to which these losses are becoming a prudential issue is illustrated by the US Federal Reserve's 2014 Comprehensive Capital Analysis and Review exercise (US Federal Reserve 2015), which revealed that operational risk losses for 25 US banks amounted to about US $\$ 150$ billion over nine quarters, the majority of which related to litigation losses and were comparable to the credit losses incurred by the banks. In part driven by these losses, bank returns are well below expected returnon-equity hurdles, and average valuations are well below historical standards".
} 
their part that the state would prevent their failure or because of a blindness to the potential impact of taking on such risks, then here was "moral hazard" on a massive scale. The term "moral hazard" refers to a structural unfairness: one person or group is able to make decisions where all or most of whatever benefits that will result will go to this person or group, and yet, if the decisions instead turn out to result in harms, these harms will be borne mainly by others. When the banks were making large profits, most of their profits (only most because there was of course tax paid) were going to their shareholders and employees. When huge net profit turned to huge net loss, the state had to pay, since the banks were deemed "too big to let fail". Those outside the banks resented getting stuck with (most of) the bill after having had no part in the decisions that generated that bill and only benefited from the earlier profits to the extent that those profits were taxed.

Pummelled by such criticisms, the banking sector lost the public's trust. A key step in improving the sector, and thus providing grounds for restoring trust, must be the correct identification of the failures that led to the banking crisis. Without the correct identification of the failures that led to the banking crisis, we are unlikely to hit upon successful safeguards against reoccurrence.

Boudewijn de Bruin has recently argued that the problem behind the crisis was not (predominantly) greed or an overweening emphasis on the profit motive, but was rather a specific kind of incompetence. The problem, he suggests, lay with a failure (on behalf of both professionals and customers) to realize basic epistemic virtues, such as:

- Love of knowledge

- Courage (in assessing evidence and revising and expressing beliefs)

- Justice (giving fair hearing to opposing positions)

- Temperance (balancing the right amount of inquiry, warrant and belief formation)

- Humility (seeking a wide range of opinions and avoiding arrogance)

- Epsitemic generosity

De Bruin's discussion is valuable at least in part because there is always a need to be reminded that individuals and businesses should

(a) be inquisitive,

(b) seek evidence,

(c) be unbiased and impartial about sources of evidence (people who aren't white, aren't male, aren't Christian, etc., shouldn't be distrusted just because they aren't white, aren't male, aren't Christian, etc.),

(d) test propositions and evidence where possible,

(e) soberly form beliefs supported by the evidence,

(f) listen to other people's criticisms of these beliefs, (g) stick to the beliefs justified by the evidence even when these beliefs are unpopular or inconvenient,

(h) be humble about one's own fallibility, and

(i) share knowledge freely with others, except when some people (e.g. customers, clients, shareholders, employees) have a right that the information be kept confidential.

However, whilst the benefits of the epistemic practices listed in (a)-(i) are unassailable, de Bruin needs to establish two further, non-trivial, theses to arrive at his account of the crisis in terms of epistemic virtue theory. First, he needs to establish the thesis that the kinds of epistemic behaviour listed in (a)-(i) are themselves best understood, from a theoretical point of view, in terms of virtue epistemology. Second, and most importantly from our current perspective, he needs to establish the thesis that the financial crisis is best viewed in terms of such a virtue epistemology, with the upshot that moves to safeguard against future problems should focus on ways to encourage the acquisition and exercise of epistemic virtues.

We will argue that de Bruin does not succeed in establishing either of these further theses. The next section looks at the relationship between good epistemic practices and the theoretical approach of virtue epistemology. "Rejecting the Epistemic Virtue Theory Approach to the Financial Crisis and Subsequent Scandals" section examines the claim that the financial crisis should be viewed in terms of a failure of epistemic virtue.

\section{Is Good Epistemic Behaviour Best Understood in Terms of Epistemic Virtues?}

Virtue epistemology holds that epistemic virtues "motivate and enable people to perform investigative actions and adopt beliefs in ways that enlarge the likelihood of gaining knowledge to the extent that this is necessary for reaching other goals they have" $(2015$, p. 70$){ }^{3}$ As we said, de Bruin points to the virtues of love of knowledge, epistemic justice, epistemic temperance, epistemic courage, epistemic humility, and epistemic generosity. We wonder whether these epistemic virtues are anything over and above the dispositions and kinds of behaviours listed in (a)-(i). If they are not, then we think de Bruin owes some further account of what is gained by the move to the more theoryladen talk of virtues. On the other hand, if the virtues are

\footnotetext{
3 Many virtue epistemologists take knowledge to be valuable for its own sake. De Bruin might agree with that idea but he doesn't rely on it. Instead he takes knowledge to be instrumentally valuable to achieve other goals (2015: 70). Most relevant here will be the goal of business, which typically is to maximize the value of shares in the business, subject to certain legal and moral side-constraints, as Milton Friedman contended.
} 
something more than the dispositions and behaviours in (a)-(i) then it would be good to be told more about what this difference is.

De Bruin periodically suggests that virtue epistemology should be understood in terms of the Aristotelian "doctrine of the mean". In many cases, this suggestion seems implausible. Here is one example. Epistemic justice consists in being unbiased and impartial about sources of evidence. We agree of course that testimony from someone should not be ignored or discounted merely because of that person's race, religion, national origin, gender, etc. But we cannot see how either epistemic justice (i.e. unbiased impartiality) is perspicuously conceived of as a mean between extremes. To take another example, epistemic generosity does not seem perspicuously described as a mean between extremes. Of course, the disposition to provide information when others (e.g. colleagues, customers, regulators) have a right to that information can be juxtaposed with the disposition to withhold information when others (e.g. shareholders, clients) have a right that the information remains confidential. But that there is this juxtaposition hardly entails that there is a virtuous mean between the extremes.

Admittedly, there are varieties of virtue epistemology that do not rely on the doctrine of the mean. Maybe some such variety can be shown to be helpful to business ethics. However, we contend that more work would be needed to show that the unobjectionable points captured by (a)(i) really are best rendered within the theoretical framework of virtue theory which de Bruin recommends.

\section{Rejecting the Epistemic Virtue Theory Approach to the Financial Crisis and Subsequent Scandals}

\section{Rejecting De Bruin's Argument for the Normative Ground of Epistemic Virtues}

For de Bruin's argument to go through, there must be a normative force for the epistemic virtues - that is to say, they must be things we are in some way required to acquire. To provide this normative grounding, de Bruin appeals to an antecedent commitment in the financial services sector to what he terms the "Argument from Liberty", where the premises of the argument are as follows:

Argument from Liberty (de Bruin 2015: 35-36)

1. It is a good thing to increase the personal responsibility people have for satisfying their own preferences.

2. Increasing freedom of choice leads to an increase in the personal responsibility people have for satisfying their own preferences.
3. Liberalization (i.e. reducing restrictions on freedom of enterprise) increases freedom of choice.

De Bruin ascribes acceptance of these premises to, amongst many others, Ronald Reagan, Margaret Thatcher, Bill Clinton, and Tony Blair (2015: 44) and suggests that these ideas have been influential in reforming policy in countries ranging from China, India, Mexico, and Ghana, to South Africa. De Bruin notes, "This reasoning inspired, amongst other things, the privatization of pension schemes in the UK and the liberalization of legal regulations on mortgage lending in the United States" (2015: 36-37). The rationale that the financial services industry offers for opposing restrictions on freedom of enterprise is that such restrictions get in the way of customers' optimizing the allocation of their resources and thus get in the way of customers' maximizing their wealth and well-being (2015: 43). So the financial services industry is de facto committed to the Argument from Liberty.

Before we engage with de Bruin's own discussion of the Argument from Liberty, we should note that the argument, as de Bruin lays it out, is incomplete as the conclusion is left implicit. What is the conclusion supposed to be? Presumably, it is:

Conclusion: liberalization is a good thing.

However, to drive this conclusion validly, the argument needs a fourth premise:

4. Something that leads to a good thing is itself a good thing.

This extra premise, in this unqualified version, would be difficult to defend. True, many good things lead to other good things. However, it is also the case that many good things are caused by things that are in themselves neither good nor bad. Furthermore, the real problem is that sometimes something bad leads to something good. Here are two of countless possible examples. War is bad and social solidarity is good, but war can lead to social solidarity. Disease (in something good) is bad and love (of a good thing) is good, but John (who is good) becomes diseased and then John's disease leads to Sukh's loving him.

In the light of such obvious counterexamples to premise 4 , we would have to qualify 4 to:

4*. Something that leads to a good thing is good in at least one respect-namely in leading to that good thing.

But now the problem for the Argument from Liberty is that:

Conclusion: liberalization is a good thing. 
needs to be more qualified. Once premise 4 is replaced with premise $4 *$, the conclusion that can be validly drawn is the much more modest:

Conclusion*: liberalization is good in at least one respect.

This much more modest conclusion is perfectly compatible with acknowledging that liberalization is bad on balance, that is, once all things are considered.

We suggest, then, that it is not possible to deliver a version of the Argument from Liberty which is both valid and capable of supporting the conclusion that most proponents of the argument presumably want (namely, that liberalization is good simpliciter, or at least on balance once all things are considered). Instead of criticizing the Argument from Liberty along such lines, however, de Bruin writes, "my interest in the argument is mainly driven here by the project of finding a normative starting point of epistemic virtue. I do think of the argument as potentially a quite powerful source of policymaking, but only if a number of epistemic assumptions be satisfied, which it is the unwarranted tendency of many commentators and policymakers to neglect." (2015, p. 36) De Bruin makes the excellent point against a general application of the Argument from Liberty that it presumes people are aware of and understand the choices they are being offered. People's doing what they want is unlikely to maximize their wealth and well-being if their preferences are based on ignorance, misunderstanding, illusion, unreliable information, or illogical reasoning (2015, p. 40). In de Bruin's words, "people need genuine knowledge to benefit from increased freedom" (2015, p. 43). Likewise, insofar as the focus is on increasing people's responsibility for their own choices and welfare, people need to know what courses of action or inaction are available to them, what the possible consequences are of these, and what the probabilities of these consequences are (2015, p. 41).

So far, we have seen that the Argument from Liberty presumes people need knowledge. If we distinguish having knowledge from having epistemic virtue, we have not yet seen why the Argument from Liberty presumes people need epistemic virtue. A plausible idea is that knowledge and understanding are very unlikely in the absence of epistemic virtue. We will return to this idea later, after raising some other worries.

A first worry is that, even if de Bruin is right that there is a de facto acceptance of the Argument from Liberty by financial institutions, it is a further question whether financial institutions are right to accept the argument. Perhaps the Argument from Liberty should be rejected (de Bruin acknowledges this question can be raised (2015: 42-43)). If the Argument from Liberty should be rejected, a further question is posed: would the normative ground for the epistemic virtues be lost if we reject the Argument from Liberty, at least as it stands? ${ }^{4}$ If the normative ground for the epistemic virtues is tied to the Argument from Liberty, de Bruin should have provided a stronger argument for accepting the Argument from Liberty itself.

A second worry here concerns how the appeal to the Argument from Liberty sits within de Bruin's overall conception of what a financial institution is. He discusses at some length how we should construe institutions and ultimately assumes (he says for the sake of argument) an extremely minimal conception of what a corporation is. Following Milton Friedman, de Bruin conceives of a corporation as a fictional body introduced to facilitate voluntary contracts. On this view, there are no properties other than this that are necessary in order for something to be a corporation. As corporations, financial institutions have no necessary goals, although of course there will be the goals of individuals within these corporations. De Bruin writes, "It is a category mistake to derive a corporate purpose from [these] multifarious individual purposes" (2015: 31).

However, we might wonder whether the "category mistake" is assigning a corporate purpose per se or assigning a purpose derived from individual goals. Admittedly, in line with the Fallacy of Composition, there need be no purpose that can be simply extracted from the goals of individual members. But avoiding the Fallacy of Composition does not preclude recognizing the possibility of some kind of emergent purpose.

A familiar case here in favour of the possibility of emergent purposes is the function of an army: X, Y, Z may each have a goal of defending only their own family and goods; however, they realize that it would be more effective to join together to prevent attack. Thus they form an army, which has an emergent goal of defending the whole territory (a goal not endorsed by any individual independent of the formation of the army). If this kind of institution-level purpose is possible, then Friedman's and de Bruin's minimal conception of a corporation can be resisted, in favour of a more substantive account that leaves room for "the proper function of a financial institution" to

\footnotetext{
${ }^{4}$ One possible reason to reject the Argument from Liberty stems from the fact that research suggests that choice maximization (beyond a certain point) is in fact detrimental to agents, e.g. work in social psychology shows that people are less satisfied when making choices in the face of very large numbers of options (choosing an ice cream in a shop that has too many flavours, buying coffee from a chain with a large number of possible drink variations) and it is wrong to think that this loss of utility occurs only "because we cannot see the wood for the trees and lack full knowledge of our decision situation" (de Bruin 2015: 43). We might have full knowledge of the different flavours; what overwhelms is the sheer variety. De Bruin is right that the problem occurs "when we do not know how to distinguish alternatives [and] start feeling overpowered and unable to choose" (2015: 43), but it's not more knowledge that will help here-it may be that nothing epistemic will improve the situation.
} 
be something more than merely facilitating voluntary contracts. 5

De Bruin might accept this point, for he explicitly notes that he advocates the minimal conception of a corporation only for the sake of argument. His aim is to show that the normative construal of the epistemic virtues can be properly grounded without making any substantial assumptions about the nature of corporations at all. If a more substantial conception of a corporation turns out to be correct (say one which allows for institutional purposes), taking on board this more substantial conception of a corporation might still be perfectly compatible with de Bruin's stance. (Whether or not this more substantial conception of a corporation is compatible with de Bruin's stance depends of course on what this conception is.)

Yet even if we set that point aside and grant to de Bruin his minimal conception of a corporation, there remains a problem here for him. Given the extremely minimal conception of a corporation he adopts, is he then entitled to maintain that financial corporations must be committed to the Argument from Liberty? If a financial corporation is nothing more than a nexus of voluntary contracts, there seems little reason to assume that this corporation possesses a commitment to anything (perhaps beyond those contracts). It seems odd that de Bruin on the one hand adopts such a minimal account of what a corporation is and yet on the other seems to adopt such a substantive view of what a corporation accepts or views as desirable. Yet if the minimal conception of a corporation is incompatible with the idea that financial corporations must be committed to the Argument from Liberty, then we do not in fact have the normative grounding for the epistemic virtues that de Bruin promised. To provide the normative ground that de Bruin promised, he has to show that financial institutions, as minimally construed, are committed to the Argument from Liberty. We are sceptical that this can be shown.

Finally, whilst de Bruin is right to note that there is a place for improved epistemic practices here and that regulators "have to acknowledge that the mere provision of information concerning freedom is only partly going to address the needs of people facing financing decisions" (2015: 90)-i.e. as we might put it: information is not the same thing as knowledge-still he seems wrong to maintain that this reveals a special place for epistemic virtues over a focus on ethics more generally. For even if de Bruin is granted the special place he wants for the Argument from Liberty, still this argument has other preconditions besides the epistemic ones. For the Argument from Liberty to work, customers need practical virtues (e.g. courage, strength of will) to exercise their choice and they must have

\footnotetext{
5 See Mayer (2013) for an excellent and thought-provoking discussion of the nature, and thus the purpose, of corporations in general.
}

the political liberty and financial resources to put into effect a preference for one basket of goods and activities rather than another. So the Argument from Liberty itself requires more than epistemic virtues. Thus, even on de Bruin's favoured conception of the landscape, knowledge matters but certainly isn't the whole story.

\section{Rejecting the Claim that Internalization of Epistemic Virtue is the Best Way to Address the Problem}

De Bruin's positive answer to the question of how things can be improved in the sector is that agents need to acquire and exercise epistemic virtues (2015: chs. 3, 4). We counter with the observation that the epistemic worries themselves could be addressed in ways that need not involve internalizing the virtues. For instance, consider the epistemic asymmetry that exists between customers and professionals in the financial sector, such that customers are often lacking in both the kind of financial literacy required to understand the products on offer to them and are often lacking in the appropriate kinds of information required to allow them to make a well-informed decision. There are two obvious ways in which to address this problem. First, an attempt might be made to improve the financial literacy of customers (potential as well as actual) of financial services. Second, customers might be encouraged to get more and better advice. Of course, both these options might be taken together-improving the financial literacy of customers and offering them better financial advice. However, de Bruin assesses them as separate options. And he argues that neither of these two alternative moves is adequate.

First, considering moves to improve financial literacy, de Bruin (2015: 72-73) cites a study showing that university students who had undergone a nineteen-hour financial literacy programme were more likely to purchase less comprehensive health insurance policies, thereby taking a higher risk. He concludes (2015: 73) that there is no proven connection between financial literacy and intelligent investment: "[T]o date, no study seems to have broached the topic of the correlation between financial literacy and wise investment".

Second, he argues against treating the provision of financial advice (customers' taking financial advice is a prime example of what he terms "outsourcing epistemic responsibility") as an adequate solution. He provides four considerations against treating the provision of financial advice as an adequate solution. First, trust in financial advisors has diminished (2015: 73). Second, those most in need of financial advice are the least likely to buy it (2015: 73-74). Third, people often don't do what advisors suggest (2015: 74). Fourth, although some evidence suggests that 
requiring customers to seek financial advice does improve financial outcomes (2015: 103), this may be through ancillary effects (e.g. that such legislation reduces the provision of financial services to high risk clients-banks stop offering mortgages to those required to seek advice).

From these considerations, de Bruin concludes that the way forward is not to try to improve customers' financial literacy or to provide customers with financial advice, but for customers to internalize and practice the epistemic virtues (2015: 74):

The question ... is not what levels of knowledge about finance are sufficient for adequate financial planning. On the contrary, I investigate the epistemic virtues leading people to acquire the knowledge and the vices that result in their failing to do so. Doing this suggests ways to strengthen financial literacy. But financial literacy is not always accompanied by epistemic virtue, nor does financial illiteracy imply epistemic vice by necessity.

As this passage indicates, de Bruin maintains that financial literacy and advice are distinct from epistemic virtue in this area, with financial literacy and advice being neither necessary nor sufficient for epistemic virtue.

Of course, we agree that financial literacy is possible without epistemic virtue ("financial literacy is not always accompanied by epistemic virtue"). However, de Bruin also claims that one can fail to have financial literacy (i.e. be in a position of financial illiteracy) and still have epistemic virtue (or at least absence of epistemic vice- - "nor does financial illiteracy imply epistemic vice by necessity"). We doubt that, in today's increasingly complex financial marketplace, there are many people who have epistemic virtue with respect to financial matters and yet do not have at least a significant degree of financial literacy. As a matter of conceptual analysis and metaphysical necessity, we acknowledge that, since literacy/illiteracy and virtue/vice are contrasts of scalar terms, there is room for argument about whether one must have at least minimal financial literacy in order to have at least minimal epistemic virtue about financial matters. As a practical matter, however, we think that nowadays no one could be plausibly described as epistemically virtuous about financial matters if this person was almost completely illiterate about such matters.

Furthermore, and even more problematic for de Bruin, if financial literacy and advice were able to solve the problems, this independence would show that a move towards epistemic virtue was not necessary for addressing the problems here. Moreover, we are not persuaded by de Bruin's arguments against trying to improve customers' financial literacy and against providing customers with financial advice. The fact that financial literacy is difficult to improve certainly does not in itself militate against attempts to improve it. Perhaps the attempt just needs more effort (after all, lots of worthwhile goals are difficult to achieve). Furthermore, only one study is cited to show that financial education doesn't help. ${ }^{6}$ So the evidence base for dismissing financial education is far too thin.

De Bruin's argument against the provision of financial advice is even weaker. First, the worry that trust in financial advisors has declined doesn't speak against provision of advice; it speaks in favour of improving levels of trustworthiness of financial advice. Second, the worry that those most in need of financial advice are least likely to buy it speaks in favour of provision of free or very inexpensive advice, not in favour of no advice at all. Third, the recognition that people often don't do what advisors advise may point to possible problems with the way advice is provided. But in general if people ignore appropriate and appropriately given advice without good reason, then they have to shoulder the liability for their decisions; otherwise, personal responsibility is undermined.

We therefore contend that the options de Bruin rejectsimproving customers' financial literacy and education and the provision of good, accessible financial advice to customers-remain firmly on the table as ways to reduce the risk of further problems in this sector. The combination of these options does not entail the acquisition or practice of full epistemic virtue by customers. Yet these options seem to us to be very valuable, especially in combination.

\section{Rejecting the Idea that an Appeal to Epistemic Virtue has Practical Application}

The correct understanding of the failings in the financial services sector during and after the crisis of 2007-2008 might well suggest practical ways to try to avoid problems in the future. Yet the degree to which de Bruin's appeal to epistemic virtues can really help us in this respect is unclear.

First, the proposal that customers should acquire the epistemic virtues needed to make wise choices themselves looks even more problematic in practice than the options de Bruin rejects. For instance, products change and multiply, terminology mutates, advertising manipulates, and fashions swirl. In the context of such change and complexity, it is highly unlikely that sufficient epistemic virtue could be developed in nearly all customers of mortgages and other financial services to protect them from ruinous contracts.

\footnotetext{
${ }^{6}$ It is also unclear in the cited study that the students really are investing unwisely: given their age (and thus the statistical improbability of serious illness in the short term) together with other calls on their resources, it may be that the best investment strategy for the students was to opt for cheaper health insurance.
} 
Second, not all of the activities that contributed to the financial crisis could be explained by lack of epistemic virtue. For instance, consider the behaviour of the credit rating agencies (CRAs) — such as Moody's, Standard \& Poor's, and Fitch - that rated complex mortgage-backed security products. The reluctance of CRAs to adjust the ratings of those products to reflect the value of the underlying assets (in particular following an upward spiral in sub-prime mortgage defaults) seems to have been the result of inherent conflicts of interest rather than a failure in epistemic virtue. ${ }^{7}$ This example illustrates how a focus on epistemic virtue alone won't address all issues.

Finally, it is difficult to see how requiring professionals and consumers to acquire and exercise epistemic virtues could be sensibly mandated by regulatory statutes. Financial regulation in the UK is focused fundamentally on duties, not on virtues. For regulations to bring about abstract and qualitative virtues such as love of knowledge, courage, temperance and humility would be difficult, unless these regulations were couched in terms of substantiate positive requirements (in which case, one might think that it was these substantive requirements, rather than the appeal to epistemic virtue per se, which really mattered here). ${ }^{8}$

So, in light of our questions about whether good epistemic practices really need to be understood in terms of virtue epistemology $(\S 1)$, about whether de Bruin establishes a normative ground for epistemic virtues ( $\$ 2 . i)$, about whether he successfully shows that the situation can only or best be improved by the customers' acquisition of epistemic virtues (\$2.ii), and about whether a requirement for epistemic virtue can realistically be embedded within regulatory statutes $(\$ 2 . i i i)$, we conclude that the case for prioritizing epistemic virtue as a means of averting another global financial crisis is far from proven.

Having argued against de Bruin's recommendation that the way forward is to prioritize epistemic virtue, we will devote the next sections to making some positive suggestions about how to move forward, both in terms of conceptualizing the issues and in terms of practical steps.

\section{Banks and Their Relationship to Society}

De Bruin argues (2015: 33-34) that the financial services industry should not be viewed as occupying a special place in the world of business: "In some sense ... things that banks do are things we could do for ourselves". For instance, the role of supplying credit between lenders and

\footnotetext{
7 This is one of the points at the heart of The Big Short, the 2015 film about the financial crisis.

8 Thanks are due to Shazia Khan-Afghan for discussion of this point.
}

borrowers could be organized and enacted on an individual level, although obviously this would be less efficient than having the relationship mediated by a bank.

We sharply disagree with the idea that the financial services industry does not occupy a special place. From a practical perspective, financial services carried out on a community-wide scale certainly couldn't be left to the whims of individuals. If every time someone needed an overdraft or a small business wanted credit they had to embark on an individual search for a personal creditor, this would be unstable and hugely inefficient and result in vastly less economic growth. The same would be true of individuals with assets that could be lent and the search for trustworthy borrowers. (De Bruin acknowledges these points, 2015: 33-34.) In addition, the role of banks in further financial services (such as providing custodial and management services to pension funds, holding government bonds) is not something that could be easily devolved to individuals. Furthermore, such services as providing safety of deposits and reasonable credit are pivotal to the functioning of productive, innovative, and efficient economies. The vast majority of people in developed economies benefit from having available the services provided by banks. In this sense, as has been recognized elsewhere, the social role of the big banks seems more akin to that of the big utilities. ${ }^{9}$ Finally, the financial services sector occupies a special place in at least some economies

\footnotetext{
${ }^{9}$ For instance, this was a topic of discussion at the World Economic Forum in 2009 and has more recently been debated in light of moves urging banks to provide banking services to the currently unbanked. For instance, in a letter to bank CEO's in 2016, the Consumer Financial Protection Bureau in the US wrote: “...having a checking account or a reloadable prepaid account enables consumers to receive wages and benefits, make payments, store funds, and manage their day-to-day lives. These functions are essential to both financial viability and economic mobility, and they represent the enormous value that your institution provides to a large number of Americans on a regular basis" (see http://files.consumerfinance.gov/f/201602_cfpb_ letter-to-banks-on-lower-risk-accounts.pdf). Note that arguing that the big banks occupy a similar social role to the big utility companies does not necessarily entail the view that they should be subject to exactly the same kinds of regulatory regimes, although the two views are often run together. For instance, in a speech in February 2016, Minnesota Federal Reserve President Neel Kashkari, addressing the problem of banks that are too big to fail, suggested as one option turning them into public utilities by forcing them "to hold so much capital that they virtually can't fail (with regulation akin to that of a nuclear power plant)"; source: https://www.theguardian.com/busi ness/2016/feb/16/finacial-crash-bank-bailout-2008-neel-kashkari-usbanks-too-big-to-fail. One reason for thinking matching regulatory regimes would not be well-advised concerns the need for innovation in the financial services sector, which does not seem to be present in the same way within the utility sector. Furthermore, a bank required to hold sufficient capital to make failure virtually impossible would probably not be profitable. At the very least, then, imposing massive capital requirements on banks would probably lead to a huge growth in alternative institutions (such as the FinTechs) which would not be classified as banks and would thus avoid crippling capital constraints
} 
because of its scale (e.g. the gross value added for financial corporations-FINCOs-in the UK in 2013 was $£ 250$ billion). ${ }^{10}$ Since the crisis, in recognition of the special importance that financial institutions have to society, taxpayers (at least in a number of countries including the UK) have become the lenders of last resort for at least some financial institutions.

The combination of these aspects of the big banks supports the idea that they have a special relationship with the societies to which they belong. Because of this special relationship to society, big banks are granted special privileges (such as government support in the form of deposit protection, etc.) but also special purposes and duties-in particular a duty to consider the social good. According to Friedman's model, the sole purpose of a company, beyond compliance with law and with ethical prohibitions, is maximization of shareholder profit. Because of the special relationship that the financial services industry has with society, Friedman's model cannot be appropriate for this sector. We should allow that there are emergent social goals for big banks, goals which relate to social goods, and which emerge because of the complex, reciprocal relationship that big banks have with society. If this is correct, then we should ask how banks can more effectively serve their social goals.

\section{Rethinking the Nature of CSR in Financial Institutions}

Carroll (1991) sets out what he calls "The pyramid of Corporate Social Responsibility (CSR)”, whereby:

1. Society requires firms to meet legal responsibilities

2. Society requires firms to meet economic/business responsibilities

3. Society expects firms to meet ethical responsibilities

4. Society desires firms to meet philanthropic responsibilities

De Bruin rejects the pyramid, because, following Friedman, he rejects any requirement for CSR. We agree with de Bruin that the pyramid model should be rejected. But our reasons are the opposite of his.

We accept CSR. What we object to in the pyramid model is its tendency to generate a silo-mentality about CSR. By this silo-mentality, we mean the presumption that the lower levels of the pyramid can be formulated and enacted without reference to any of the higher levels. In

Footnote 9 continued and yet which could offer many of the products and services banks offer more cheaply and easily.

10 See http://www.ons.gov.uk/ons/dcp171776_421524.pdf. contrast with the silo-model for CSR, a better model for CSR is one where the ethical dimension of decisions is integrated throughout the business. This integrated model for CSR speaks against construing CSR as limited to philanthropic activities. Rather, the CSR activities of a firm should promote societal values through the appropriate deployment of the firm's expertise and assets. We suggest that CSR in banks should be more like the pro bono work undertaken in the legal sector, where practitioners not only contribute their time or money to worthy causes but also utilize their professional skills for the wider good.

Rethinking the nature of CSR in the financial sector along these lines could provide a new way to ameliorate problems surrounding financial literacy and thus provide a way to address the problems of epistemic asymmetry that de Bruin rightly identifies in this area. ${ }^{11}$ For instance, as part of their CSR requirements, firms might be encouraged or required to provide basic financial education and impartial advice to the poorest sectors of society, in order to ensure that financial knowledge and understanding (and not just access to information) are improved. ${ }^{12}$ If banks took on this role in conjunction with existing bodies that enjoy high levels of public confidence and trust, such as the Citizens Advice Bureau, and if bank employees doing this work were removed from any distorting pressures relating to selling or product placement, we think that banks' taking up this proposal and in a conscientious spirit could provide a significant step on the road towards re-establishing warranted public trust in banks. If banks helped to address the chronic lack of basic financial advice for those on the lowest income levels, this would help to restore and renew the social relationship for banks.

Another practical step that might follow from reconceiving the relationship between banks and wider society concerns the nature of penalties for misbehaviour. Currently the primary sanction for serious misbehaviour involves ever-increasing levels of financial penalty. Yet increased fines do not seem to be preventing scandals, and

\footnotetext{
${ }^{11}$ Despite significant government initiatives in this area (at least in the UK), there is reason to think that financial literacy in general remains poor. For example, a 2016 survey by the UK-based Money Advice Service found that a third of 16-17 year olds surveyed had never put money into a bank account and that two in five didn't even have a current account (see https://www.moneyadviceservice.org.uk/ blog/the-kids-aren-t-alright-just-40-are-taught-money-skills-atschool).

12 Advice and training here might include looking at how to record and monitor income versus outgoings, how to balance holding savings whilst also running a credit card balance, the different kinds of risk associated with different kinds of financial product and, crucially, the investment options for pensions. In this regard, we would highlight programmes like Lloyds "Money for Life" (see https://www.money forlifeprogramme.org.uk/) as a hugely positive step, but argue for the provision of this kind of service for low income adults as well as sixth form students.
} 
public trust continues to be strikingly low. An alternative model, if the rules that govern banks were construed as ways to maintain social cohesion and to benefit all of society, would be to offer an alternative response to misbehaviour. Instead of a simple fine, firms should instead be required to pay for remedial exercises where staff are encouraged and enabled to reflect on the rules in place, exploring the reasons those rules exist and assessing the true cost to society of flouting them. ${ }^{13}$ There is a useful analogy to be drawn here, we feel, with recent moves in the UK to promote compliance with road traffic regulations, where offenders are offered, as an alternative to a fine plus penalty points on the licence, the option of attending and paying for a Speed Awareness Course. As AA DriveTech states:

The National Speed Awareness Scheme aims to reduce the speed at which people drive by encouraging them to alter their attitudes towards excessive or inappropriate speed. Offered as an alternative to a speeding fine and penalty points, it helps drivers to gain a fuller understanding of why people drive above the speed limit and the true potential consequences of speeding. ${ }^{14}$

From a peak of 2,087,000 in 2005, the number of speeding offences fell rapidly to $1,270,000$ in 2009. Although full research remains to be undertaken, the Parliamentary Advisory Council for Transport Safety takes speed awareness courses to have played a major role in this reduction (see Speed and Safety: evidence from published data, Mitchell 2012). We suggest that similar moves should be considered to improve compliance with financial regulation.

Bank employees, at all levels, need to be reminded, especially when misbehaviour comes to light, why the rules exist and who and what suffers if they are broken. And

\footnotetext{
13 This would help to counter the well-known worry that no amount of regulation will curb behaviour which seeks to game the rules and indeed that regulation itself may actually encourage a climate of such gaming. As Mayer (2013: 68) puts it "Since neither incentives nor reputations can be relied on to align the interests of companies with those of society more generally, we turn to third parties, namely governments and regulators, to do this for us. However, all this does is to promote the development of another profitable industry, namely regulatory avoidance, and mechanisms for minimizing the impact of regulation on the pursuit of private gains...The most significant source of failure is [therefore] that we have created a system of shareholder value driven companies whose detrimental effects regulation is supposed to but fails to correct, and in response we seek greater regulation as the only instrument that we believe can address the problem. We are therefore entering a cycle of the pursuit of ever-narrower shareholder interests moderated by steadily more intrusive but ineffective regulation".

${ }^{14}$ See http://www.theaa.com/aadrivetech/driver-awareness/speedawareness-course.html.
}

bank employees need to be helped to improve their moral sensitivity. An improved moral sensitivity should help them in working through complex cases, where competing moral demands are operative, to arrive at the right decisions. (As de Bruin (2014: 261) notes "In order to do the right thing... businesses have to gain knowledge about their stakeholders [too] - that is, about the harms and benefits of the firm's operations to people affected by them".) Certainly, guided discussion in an atmosphere of cooperation and patience and careful reflection can improve the ability to identify moral issues, to structure relevant considerations, and to avoid fallacies in moral reasoning. ${ }^{15} \mathrm{We}$ suggest that moral development, rather than the focus on purely epistemic virtue which de Bruin advises, will help to rebuild warranted trust in this sector and help to safeguard against further scandals occurring.

\section{Conclusion}

There can be no guarantee that there will be no future financial crises. Even now, the housing market hasn't fully corrected, and many companies (and countries and people) have levels of debt that will not be sustainable if there are significant rises in interest rates. Some prudent steps have been taken by governments and regulatory bodies, such as (1) increasing the capital requirements on banks, (2) changes to the provision of bonuses, with greater clawback potential, and (3) the introduction in the UK of the Senior Managers Regime. Alas, very recently there have also been steps backwards and there remains, we suggest, significant work to be done on the culture within banks to prevent further problems. Reflecting on the role that financial services institutions play in western societies, on the special privileges and duties banks have, and on taxpayers' status in at least some cases as lenders of last resort, people are right to demand better behaviour within banks. People are also right to want to see evidence that banks take more seriously their commitment to the public good. The concrete steps we have outlined above are ways in which banks can demonstrate that they are serious about such improvements.

\footnotetext{
15 Carefully tailored courses that force attendees to think how they could legitimately justify their decisions to someone face-to-face would help to raise the "moral intensity" (see Jones 1991) of ethical problems faced by bankers and others in financial services. That is to say, guided group discussion could help people to reflect better on the full moral dimensions of the issues they face, preventing courses from descending into a mere tick-box exercise (as on-line ethics management programmes are apt to do). The carefully tailored courses we envisage could also help to support a return to the kind of professional integrity stressed by O’Neill (2014).
} 
Funding This study was funded by an internal Research Dean Award, University of Reading.

\section{Compliance with Ethical Standards}

Conflict of interest Both authors declare that they have no conflict of interest.

Ethical approval This article does not contain any studies with human participants or animals performed by any of the authors.

Open Access This article is distributed under the terms of the Creative Commons Attribution 4.0 International License (http://crea tivecommons.org/licenses/by/4.0/), which permits unrestricted use, distribution, and reproduction in any medium, provided you give appropriate credit to the original author(s) and the source, provide a link to the Creative Commons license, and indicate if changes were made.

\section{References}

Carrroll, A. (1991). The pyramid of corporate social responsibility: Towards the moral management of organizational stakeholders. Business Horizons, 34, 39-48.

De Bruin, B. (2014). Ethics management in banking and finance. In N. Morris \& D. Vines (Eds.), Capital Failure: Rebuilding Trust in Financial Services (pp. 255-276). Oxford: OUP.
De Bruin, B. (2015). Ethics and the Global Financial Crisis: Why Incompetence is Worse than Greed. Cambridge: Cambridge University Press.

G30 Working Group (2015). Banking conduct and culture: A call for sustained and comprehensive reform. http://group30.org/publica tions/detail/166.

Jones, T. (1991). Ethical decision making by individuals in organizations: An issue-contingent model. Academy of Management Review, 16, 366-395.

Mayer, C. (2013). Firm Commitment: Why the Corporation is Failing us and How to Restore Trust in it. Oxford: OUP.

McLannahan, B. (2015). Banks' Post Crisis Legal Costs Hit \$300bn. The Financial Times, June 8.

Mitchell, C. (2012). Speed and Safety: evidence from published data. Parliamentary Advisory Council for Transport Safety \& RAC publication. http://www.racfoundation.org/assets/rac_foundation/ content/downloadables/speed_and_safety-mitchell-aug2012.pdf.

O'Neill, O. (2014). Trust, trustworthiness, and accountability. In N. Morris \& D. Vines (Eds.), Capital Failure: Rebuilding Trust in Financial Services (pp. 172-192). Oxford: OUP.

US Federal Reserve. (2015). Comprehensive capital analysis and review 2015: Assessment framework and results, March 11. Washington, DC: US Federal Reserve.

Wall Street, Fleet Street and Main Street: Corporate Integrity at a Crossroads, 2012. Labaton Sucharow LLP. http://www.labaton. com/en/about/press/upload/US-UK-Financial-Services-IndustrySurvey.pdf. 